\title{
Provision of Liquidity through the Primary Credit Facility during the Financial Crisis: A Structural Analysis*
}

\author{
Erhan Artuç \\ Assistant Professor \\ Koç University \\ Department of Economics \\ Sariyer, Istanbul, Turkey 34450 \\ E-mail: eartuc@ku.edu.tr \\ and \\ Selva Demiralp \\ Associate Professor \\ Koç University \\ Department of Economics \\ Sariyer, Istanbul, Turkey 34450 \\ E-mail: sdemiralp@ku.edu.tr
}

October 2008

\begin{abstract}
Over the course of the recent liquidity crisis, the Federal Reserve made several changes to its primary credit lending facility such as narrowing the spread between the primary credit rate and the target funds rate, increasing the terms of lending, and widening the range of acceptable collateral. In this paper, we use the model developed by Artuç and Demiralp (2008) to provide a structural assessment of the effectiveness of these changes. Our results suggest that most of these changes were highly effective in stabilizing the federal funds market.
\end{abstract}

Keywords: Discount Window, Primary Credit, Federal Funds Market

JEL Codes: E40, E58

\footnotetext{
${ }^{*}$ We would like to thank Seth Carpenter and Refet Gürkaynak for their feedback and comments.
} 


\section{Introduction}

In response to the recent liquidity crisis, central banks designed a variety of tools for supplying liquidity to financial institutions. The Federal Reserve introduced several programs such as the Term Auction Facility, the Term Securities Lending Facility, and the Primary Dealer Credit Facility while enhancing the discount window and open market operations. This paper focuses on the effects of changes in the discount window facility on financial markets. We investigate whether the improvements constitute a fundamental change to the way the Federal Reserve traditionally provided liquidity through the primary credit lending facility and try to answer whether the Federal Reserve would be well-served to keep these changes to its borrowing facility indefinitely.

In January 2003, the Federal Reserve revised its discount window lending program. This facility was intended to improve the working of the discount window which had lost its functionality under the old regime prior to 2003. Before 2003, borrowing from the Fed took place at a rate below the market rate (called the “discount rate”), and Fed officials applied a non-price rationing mechanism by asking detailed questions to potential borrowers about their financial well-being before granting them a loan. Slowly, this administrative process pushed depository institutions away from the discount window because borrowing from the Fed was perceived as a signal of financial weakness by market participants (see e.g.

Goodfriend, 1983; Pearce, 1993; Dutkowsky, 1993; Peristiani, 1998; Clouse and Dow, 1999; Furfine, 2003; Dow, 2001; Darrat et al., 2004).

The new borrowing facility was designed to eliminate the reluctance to borrow from the Fed with a new "no questions asked” policy towards eligible borrowers. However, despite the assurance by the Fed that the new facility would eliminate all 
administrative costs of borrowing, some argued that the stigma could not be eliminated completely (see e.g. Furfine, 2001, 2003). Recently, Artuç and Demiralp (2008) investigated this question and showed that the stigma of borrowing that was attributable to the Fed's administrative policy and restrictions declined substantially in the period after 2003.

In this paper, we rely on the model developed by Artuç and Demiralp (2008) as our baseline model and perform out of sample simulations to asses the effects of changes in the primary credit facility since August 2007. Our results are highly consistent with the predictions in Artuç and Demiralp (2008) that the new discount window is functional and and plays an essential role in controlling the volatility in the federal funds market.

\section{Recent Changes in the Primary Credit Facility}

The primary credit facility that is established in 2003 offered credit to banks in good financial conditions at a rate that was 100 basis points above the FOMC's target federal funds rate (“primary credit rate”). Primary credit was made available to financially sound depository institutions at an above-market rate but with very little administration and no restrictions on the use of the proceeds (see Madigan and Nelson, 2002). Because the interest rate charged on primary credit was above the market price of funds, it replaced the rationing mechanism for obtaining funds from the central bank and eliminated any administrative review by the Fed.

In the outbreak of the liquidity crisis in August 2007, the Federal Reserve lowered the spread between the primary credit rate and the target funds rate from 100 to 50 basis points and extended the terms of the loans to 30 days. In March 2008, the Federal Reserve once again narrowed the spread, this time to 25 basis points and 
extended the maximum term of loans to 90 days. Recently in September 2008, the Federal Reserve broadened the types of eligible collateral for discount window borrowing. All of these moves were motivated with the desire to make the discount window credit more accessible to depository institutions.

The steps taken by the Federal Reserve to make discount window credit more accessible did lead to an increase in the volume of discount window borrowing, as shown in Figure 1. The upper panel in the figure shows total outstanding primary credit since the establishment of the facility in 2003. Due to the enormous increase in borrowing during the crisis period, the middle and the lower panels split the sample period in August 2007 to make the earlier period more visible.

While the massive increase in the volume of borrowing supports the argument that the stigma of borrowing has been eliminated, one should be cautious in not declaring a victory too quickly. Figure 2 shows the highest traded funds rate against the primary credit rate. It reflects that despite the enormous increase in the volume of borrowing, some trades in the funds market took place at rates above the primary credit rate on occasion. What is comforting about these findings, however, is that they are consistent with the predictions of our earlier work. As indicated in Artuç and Demiralp (2008), the reluctance to borrow from the Federal Reserve has two components. The non-price mechanism that is described earlier is the component that is attributable to the Federal Reserve officials' implementation of discount lending. Artuç and Demiralp (2008) showed that this component has declined significantly after the establishment of the new facility in 2003. Meanwhile, a second type of stigma arises from the asymmetric information problems associated with discount window borrowing. Specifically, while most banks borrow from the discount window, sometimes the facility is also used by troubled or failing institutions. 
Because market participants cannot fully differentiate healthy from troubled borrowers, they may view borrowing as a potential sign of weakness for any bank that visits the window. If this type of stigma increases at the early stages of a financial crisis while the institutions are trying to signal that they are in good shape, it could explain the spikes in the funds rate over the primary credit rate as seen in Figure $1 .{ }^{1}$ In addition, it is plausible to think that the capital crunch during a financial crisis may leave some institutions without sufficient collateral to apply for a primary credit loan and hence these institutions may bid for higher rates in the federal funds market, which is unsecuritized.

\section{The Model}

The model that we describe in this section closely resembles the one developed in Artuç and Demiralp (2008), which can be viewed as an extension of the model proposed by Clouse and Dow (1999). More details about the model can be found in Artuç and Demiralp (2008). We consider a simple framework where bank i’s goal is to keep its daily reserves holdings at a level $L_{1}$. Daily reserve balances do vary over the course of the maintenance period (see Carpenter and Demiralp, 2006). However, from the borrowing viewpoint, a bank's decision to borrow from the Fed is a static decision based on the liquidity conditions on each day. Therefore, we do not differentiate across the days of the maintenance period except for the settlement Wednesday which may necessitate higher borrowing because banks have less

\footnotetext{
${ }^{1}$ Indeed, when we take a closer look at the days with spikes in the funds rate, we note that market commentaries are consistent with elevated asymmetric information problems. An extreme example is October 25, 2007 when the highest traded funds rate exceeded the primary credit rate by almost ten percentage points. On this day, Wrightson ICAP reported that "the stigma of discount window borrowing was heightened by the news that the New York Fed had extended $\$ 400$ million of secondarycredit loans on Wednesday. If word got out that a given institution had tapped the window on Thursday, the market might speculate that the bank in question was the same one that had been forced to make use of the higher-cost secondary credit program for shaky institutions the day before. The reputational damage of a leak of that nature would be disastrous.” (Wrightson ICAP, Fed Funds Monitor, www.wrightson.com)
} 
flexibility in absorbing any reserve shortages on the last day of the maintenance period. On this day, the desired level of reserve holdings are determined by $L_{2}$.

Banks' balance holdings follow a stochastic process. During the day, there are aggregate and individual shocks to the average level of reserve balances $(\bar{R})$, which sets the end of day balance of bank $i$ equal to:

$$
R_{t}^{i}=\bar{R}+U_{t}+V_{t}^{i}
$$

where $U_{t} \sim N\left[0, X_{U}\right]$ is an aggregate $\operatorname{shock}^{2}$ and $V_{t}^{i} \sim U\left[-X_{V}, X_{V}\right]$ is an individual shock where $X_{U}$ and $X_{V}$ represent the support of the mean zero uniform distribution. Hence, the individual bank becomes a lender in the funds market if $R_{t}^{i}>L$ and demands funds if $R_{t}^{i}<L$ for $L=L_{1}, L_{2}$

Banks that are short of reserves have two options: they either choose to borrow from the funds market or they borrow from the Federal Reserve. If the bank chooses to borrow $\phi_{t}$ dollars from the funds market, the cost per dollar is the market interest rate $r_{t}$. Alternatively, if the bank borrows $\phi_{t}$ dollars from the Federal Reserve, the cost per dollar is the discount rate (or the primary credit rate after 2003), $r_{f}$, plus a fixed cost $c$. Thus, total cost per dollar is $r_{f}+\frac{c}{\phi_{t}}$. Because of the fixed cost, partial borrowing from the Federal Reserve is not optimal and a bank either prefers to borrow entirely from the Federal Reserve or from the funds market. ${ }^{3}$

In addition to borrowings from the Federal Reserve that are driven by market conditions, there are also borrowings due to technical difficulties such as network

\footnotetext{
${ }^{2}$ Because the original model is estimated by removing the outliers, we cut $0.5 \%$ from the tails of the normal distribution.

${ }^{3}$ Without loss of generality, one may think of the fixed costs of borrowing to vary with each bank, reflecting the particular bank's relative hesitance to borrow from the discount window based on factors such as the size of borrowing, the history of borrowing, or the availability of credit lines in the funds market. While we model it in a homogenous manner for simplicity, modeling it in a heterogenous manner is also trivial and it does not change any of the implications of our model.
} 
problems which force banks to borrow from the Fed regardless of market conditions. In order to capture this type of borrowing, we assume that a random fraction, $p_{t}$, of the banks will face a technical problem in the system where $p_{t}$ has a uniform distribution: $p_{t} \sim \mathrm{U}[0, \mathrm{~F}]$.

We assume that there is a continuum of banks, indexed from 0 to 1 . Thus there are an infinite number of banks with zero individual measure whose measure integrates to 1 . Indexing is done according to reserve balance levels such that a bank with the lowest level of reserve balances is indexed to 0 and the one with the highest level of reserve balances is indexed to 1 . Figure 3 shows the distribution of these banks according to their balance levels. Accordingly, those with reserve balances higher than $L$ supply funds in the fed funds market, where the total supply is the area of the triangle on the right. Meanwhile, those with balances lower than $L$ demand funds. There is a threshold level $T$ such that banks with reserve shortages greater than $T$ go to the discount window. Hence, the area of the trapezoid shows the demand for funds from the Fed, while the triangle adjacent to the trapezoid shows the demand for funds from the market. In the figure, we omit one dimension of the model, which is borrowing from the Fed due to technical difficulties. The actual demand from the market is the area of the triangle on the left times (1-p).

Total demand for funds has two components. It can be met in the funds market or it can be met at the discount window. Total supply of funds in the funds market needs to be at least as big as the size of total borrowing in the funds market. The equilibrium federal funds rate, $r_{t}$, is determined by the market equilibrium when the total supply of funds is equal to the total demand for funds. In modeling the borrowing behavior, our focus is on individual trades in the funds market and on days 
of market tightness because these are the days on which borrowing from the Fed are more likely. Therefore, we set the daily high funds rate equal to:

$$
r_{t}^{\text {high }}=r_{t}+\omega_{t} \quad \text { where } \omega_{t} \sim(0, s)
$$

Equation (2) notes that the maximum funds rate that is registered for a given day will differ from the equilibrium funds rate depending on the reserve need and the bargaining power faced by the counterparties of that particular trade.

Turning to the days of market softness, on these days trades are almost always cleared in the funds market unless there is a technical problem. For that reason and without loss of generality, if the supply is larger than the demand, we simply set the funds rate $\left(r_{t}\right)$ equal to the marginal benefit of holding balances $(\gamma)$ as in Clouse and Dow (1999) and do not deal with the market softness that would result as a consequence of the market surplus. Hence, a bank can offer reserves in the funds market if the market rate is greater than ${ }^{4}{ }^{4}$

If the fixed costs of borrowing declines in the period after 2003, then, everything else remaining the same, this implies a decline in the volatility of the funds rate in the post-2003 period and an increase in the sensitivity of Fed borrowing to the funds rate. This implied change in volatility and the revival of the borrowing function allows us to identify the size of the implicit cost before and after 2003.

The decline in fed funds volatility is also influenced by certain other developments over time such as better liquidity management by the Trading Desk (see Demiralp and Farley, 2004), improvements in internal information systems (including those that track the balance in a bank’s Federal Reserve account), or banking industry

\footnotetext{
${ }^{4}$ In the estimation of the model, we set $\gamma$ equal to the federal funds rate target.
} 
consolidation. To capture such changes, at least partially, we allow the distributions of $U_{t}$ and $V_{t}^{i}$ to get wider or narrower in a linear fashion over time. That is we let:

$$
X_{U}=A+\frac{D}{1000} t \quad \text { and } \quad X_{V}=B+\frac{E}{1000} t
$$

where $t$ is the time trend, $X_{U}$ and $X_{V}$ are defined after equation 1 .

To identify the potential decrease in the stigma associated with discount window borrowing, we consider the following specification for the implicit borrowing cost $c$ :

$c=c_{1}$, prior to 2003

$c=c_{2}$ after 2003

In order to estimate our model, we use “Indirect Inference” (henceforth II) which can be considered as a more generalized form of the Generalized Method of Moments (GMM). II uses the estimates of an auxiliary model (rather than moments) to compare the actual and the simulated data. Because we can think of the moments of the data as the parameters of a simplified auxiliary model, Method of Simulated Moments (or GMM) can be considered as special cases of II. Note that an auxiliary model does not need to be "correct" for II to give consistent results. So long as the selected auxiliary model summarizes the data well, the estimates of the actual model will be consistent and asymptotically normal (for more details on II, see Gourieroux, Monfort and Renault, 1993; Smith, 1993).

We contemplate a simplified borrowing function as the auxiliary model. The auxiliary borrowing function summarizes how borrowing from the Fed changed over time and after the policy change in 2003 through a simple OLS regression. In addition to the OLS estimates, we use the mean and the variances of borrowing and the spread between the daily high funds rate and the target as part of the auxiliary model. The estimation strategy is to find the parameters that will make the 
simulations of the model and the actual data look as similar as possible when viewed through the auxiliary model's OLS estimates and moments. Specifically, our auxiliary model is:

$$
\begin{aligned}
& \varsigma_{t}=\beta_{1}+\beta_{2} \tilde{r}_{t}+\beta_{3} \frac{t}{100}+\beta_{4} \frac{t}{100} \tilde{r}_{t}+\beta_{5} D^{2003} \tilde{r}_{t}+\beta_{6} D^{\text {Settl.wed. }}+\varepsilon_{t} \\
& \beta_{7}=\frac{1}{T} \sum \varsigma_{t}, \beta_{8}=\frac{1}{T} \sum \tilde{r}_{t} \\
& \beta_{9}=\frac{1}{T} \sum\left(\varsigma_{t}-\beta_{6}\right)^{2}, \beta_{10}=\frac{1}{T} \sum\left(\tilde{r}_{t}-\beta_{7}\right)^{2} \\
& \beta_{11}=\frac{1}{T} \sum \tilde{r}_{2 t}, \beta_{12}=\frac{1}{T} \sum\left(\tilde{r}_{2 t}-\beta_{7}\right)^{2} \\
& \beta=\left[\beta_{1} \beta_{2} \ldots \beta_{12}\right],
\end{aligned}
$$

where $\varsigma_{t}$ is the amount of borrowing from the Fed normalized by required operating balances, $\tilde{r}_{t}$ is the spread between the funds rate and the funds rate target, $t$ is the time trend, $D^{2003}$ is a dummy for days after the policy change, $D^{\text {Settl.Wed. }}$ is a dummy for the Settlement Wednesday, $\varepsilon_{t}$ is an iid random shock, $T$ is the sample size, and $\tilde{r}_{2 t}$ is the lowest $50 \%$ of $\tilde{r}_{t} \cdot \tilde{r}_{2 t}$ is added to the model to capture the volatility in the funds rate in the absence of market tightness.

Let $\hat{\beta}$ be an OLS estimate of $\beta$ from the actual data and $\tilde{\beta}$ be an estimate of $\beta$ from the simulated data. We pick the model's parameters $\left[A B c_{1} c_{2} D E F \bar{R} s L_{2}\right]$ such that $(\hat{\beta}-\tilde{\beta}) W(\hat{\beta}-\tilde{\beta})^{\prime}$ is minimized, where $\mathrm{W}$ is the weighting matrix that is equal to the inverse of the covariance matrix of $\beta$. 
In estimating the model, we exclude those days when the daily high rate exceeded the target rate by more than $25 \%$ to obtain a more realistic distribution for the shocks in the model. Our estimation results (shown in the appendix) suggest that the implicit fixed cost of borrowing declines about 90 percent (from 0.054 to 0.007) after the policy change in 2003. This is strong evidence that the Fed's new policy was indeed successful in reducing the stigma associated with discount window borrowing.

\section{Simulation Analysis}

In this section, we use our model to analyze the role of the Federal Reserve's primary credit lending facility in calming money markets in the face of the liquidity crisis. Specifically, we ask the following questions:

1) What are the effects of the establishment of the new lending facility on total borrowing and interest rates? In particular, what would the crisis picture look like if the implicit costs of borrowing had not been reduced with the new regime in 2003 ?

2) What are the implications of decreased costs of borrowing (through increased terms and extended set of eligible collateral) in the funds market)?

3) What are the effects of the narrowing of the spread between the primary credit rate and the target rate in calming the money market?

4) What will be the implications of interest payment on reserves for discount window borrowing?

We first remind that the model described in the previous section is designed to capture the "normal times" of healthy functioning markets. Our estimation period 
captures a period of relatively stable structural environment. The sample period starts on June 30, 1998 with the switch from contemporaneous reserves accounting to lagged reserves accounting. It ends on March 19, 2007, a few months prior to the first outbreak of the liquidity crisis in August 2007. Indeed, if we use the estimates from our model for out-of-sample simulations, the severity of the crisis and the model's inability to forecast this environment becomes even clearer. Figures 4 and 5 compare the actual data with the model's out-of-sample simulations for the deviation of the daily high funds rate from the target and for the outstanding primary credit respectively. While our model is a daily model, we present the results in terms of monthly averages to provide visual clarity. The vertical line corresponds to the end of our estimation period in March 2007. As we would expect, there is a wild discrepancy between the data and the model's simulations indicating that the period after August 2007 represents quite extraordinary circumstances which cannot be proxied by the structural estimates from the period prior to August 2007.

The sizable gap between the data and the simulations for the crisis period suggest that we should first incorporate the crisis circumstances into our model before we can conduct any counterfactual experiments about the efficiency of the Federal Reserve's policies. During the crisis, it is natural to expect the volatility of the aggregate shock $U_{t}$ to increase. Furthermore, the widening of the range of eligible collateral as well as the increase in the terms of lending are expected to reduce the implicit costs of borrowing by making it more convenient to apply for and lenghten the duration of a loan. When we double the standard error of the aggregate shock $U_{t}$ and reduce the costs of borrowing by one half, we obtain much more reasonable estimates for the interest rate spread and the volume of borrowing for the crisis period (Figures 6 and 7). We call our results from this exercise the benchmark simulations. 
We now proceed and analyze the questions that were raised at the beginning of this section. The first question that we tackle is the effects of the policy change in 2003 in mitigating the crisis after 2007. In other words, had the Fed not changed its lending policy in 2003, what would the picture look like in the funds market? Based on our findings in Artuç and Demiralp (2008), we would expect the volatility in the funds market to worsen significantly in the absence of the new regime because the current practice allows the needy institutions to utilize this service without much hesitation. Figure 8 confirms our expectations. In this figure, we plot the actual spread between the daily high funds rate and the target (the dotted line) as well as the simulations that are generated by our benchmark model (the dashed line). In addition, we show the spread under the counterfactual experiment where the costs of borrowing remained at their pre-2003 levels (the bold line). As can be seen, the counterfactual series skyrockets during the crisis period suggesting that the Federal Reserve's switch to the new lending regime was very effective in containing the severity of the crisis in the money market.

Turning from prices to quantities, the volume of borrowing cannot be different between the two regimes because banks need to borrow the necessary amount of reserve balances to avoid an overdraft or a reserve deficiency in our model. For this reason, in reporting our simulation results we only present the spread between the daily high funds rate and the target rate and do not show the borrowing behavior when the latter is unaffected under different scenarios.

Next, we analyze the effectiveness of the changes in the primary credit facility that the Federal Reserve has introduced since the beginning of the crisis. Recall that our benchmark model implied a 50\% decline in borrowing costs during the crisis period. In assessing the implications of extended terms of borrowing and a wider set 
of eligible collateral, we keep the cost of borrowing at its pre-crisis level and simulate the interest rate spread under this scenario. Figure 9 displays the results from this exercise. The elevated volatility under the counterfactual scenario indicates that extending the terms of borrowing and the list of eligible collateral were very effective means in controlling the volatility in the funds market.

While the terms of borrowing were extended, the Federal Reserve also narrowed the spread between the primary credit rate and the target rate from 100 basis points to 25 basis points over the course of the crisis. Our earlier findings in Artuç and Demiralp (2008) would suggest that the primary credit rate works as an upper bound in the absence of market stigma and that a decline in this rate should decrease deviations of the funds rate from the target. Our next simulation keeps the spread between the primary credit rate and the target unchanged at 100 basis points. As shown in Figure 10, the counterfactual spread is at least as high as the benchmark simulation, if not higher. This elevated volatility suggests that narrowing the spread was effective, even though the difference is not as outstanding as in the previous experiments probably due to the increased need for collateral under the crisis circumstances. That is, because federal funds borrowing is unsecuritized whereas discount window borrowing requires collateral, certain banks may still need to borrow in the funds market by paying a higher premium if they do not have the sufficient collateral for discount borrowing.

Recently, the Federal Reserve has been granted the authority to pay interest on reserve balances. In addition to placing a lower bound on the funds rate, interest payments on reserve balances are expected to increase the demand for balances simply because the cost of holding these balances are now lower. Our last exercise considers the impact of a higher level of balances in controlling the funds rate 
volatility. While it is hard to guess the precise magnitude of the change in reserve balances, we increase the average normalized reserve balances by $10 \%$ in our counterfactual experiment. Figure 11 shows that the control over interest rates improve while Figure 12 shows that the need for borrowing declines if the average balance holdings increase as predicted under this new regime. Together, these results suggest that any policy change that causes an increase in reserve holdings, such as interest payment on reserves, is quite helpful in controlling money markets.

\section{Conclusions}

In this paper, we analyzed the effectiveness of various changes adopted by the Federal Reserve since the outbreak of the liquidity crisis in August 2007. We showed that the extensions of the terms of borrowing and the list of eligible collateral were the most effective tools in calming the money market while narrowing of the spread between the primary credit rate and the target was not as effective. Would the Federal Reserve be well-served to keep these changes to its borrowing facility indefinitely? Our results suggest that the spread between the primary credit rate and the target rate can be increased back to 100 basis points without much impact on financial markets. One might also argue that the wider set of acceptable collateral is probably a factor that matters the most under crisis circumstances and it would not be of vital importance once the crisis is put behind. Meanwhile, the recent policy change of interest payment on reserves should make it easier for the Desk to maintain the target permanently, not only by placing a lower bound for the funds rate but also by increasing the required reserve balances which more predictable relative to transactions-related demand. In turn, this higher level of balances should reduce the demand for borrowing and the ease the consequent tightness in the funds market. 


\section{References:}

Artuç, Erhan and Selva Demiralp. (2008). “Discount Window Borrowing after 2003:

The Explicit Reduction in Implicit Costs.” Koc University ERF Working paper: 0708

Carpenter, Seth and Selva Demiralp. (2006a). "The Liquidity Effect at a Daily

Frequency.” Journal of Money, Credit, and Banking, 38 (June), 901-920

Clouse, James.A. and James.P. Dow. (1999). "Fixed Costs and the Behavior of the Federal Funds Rate.” Journal of Banking and Finance, 23, 1015-1029

Darrat, Ali F., Khaled Elkhal, Gaurango Banarjee, and Maosen Zhong. (2004).

"Why do US Banks Borrow from the Fed? A Fresh Look at the 'Reluctance' Phenomenon.” Applied Financial Economics, 14, 477-484

Demiralp, Selva and Dennis Farley. (2005). “Declining Required Reserves, Funds Rate Volatility, and Open Market Operations.” Journal of Banking and Finance, 29, $1131-1152$.

Dow, James P. (2001). “The Recent Behavior of Adjustment Credit at the Discount Window.” Journal of Macroeconomics, 23, 199-211

Dutkowsky, Don H. (1993). “Dynamic Implicit Cost and Discount Window Borrowing: An empirical investigation.” Journal of Monetary Economics, 32,105120

Furfine, Craig H. (2001). “The Reluctance to Borrow from the Fed.” Economic Letters, 72, 209-213 
Furfine, Craig H. (2003). “Standing Facilities and Interbank Borrowing: Evidence from the Federal Reserve’s New Discount Window.” International Finance, 6 (3), $329-347$

Goodfriend, Marvin. (1983). “Discount Window Borrowing, Monetary Policy, and the post-October 6, 1979 Federal Reserve Operating Porcedure.” Journal of Monetary Economics, 12, 343-356

Gourieroux, C., Monfort, Alain, and E. Renault.(1993). “Indirect Inference.” Journal of Applied Econometrics, 8, 85-118

Madigan, Brian and William Nelson. (2002). "Proposed Revision to the Federal Reserve’s Discount Window Lending Programs.” Federal Reserve Bulletin, July, 313-319

Pearce, Douglas K.. (1983). “Discount Window Borrowing and Federal Reserve Operating Regimes.” Economic Inquiry, 31, 564-579

Peristiani, Stavros. (1998). “The Growing Reluctance to Borrow at the Discount Window: An Empirical Investigation.” The Review of Economics and Statistics, 611620

Smith, Anthony. (1993). “Estimating Nonlinear Time Series Models Using Simulated Vector Autoregressions.” Journal of Applied Econometrics, 8, 63-84 
Figure 1: Primary Credit Outstanding (Weekly Average)
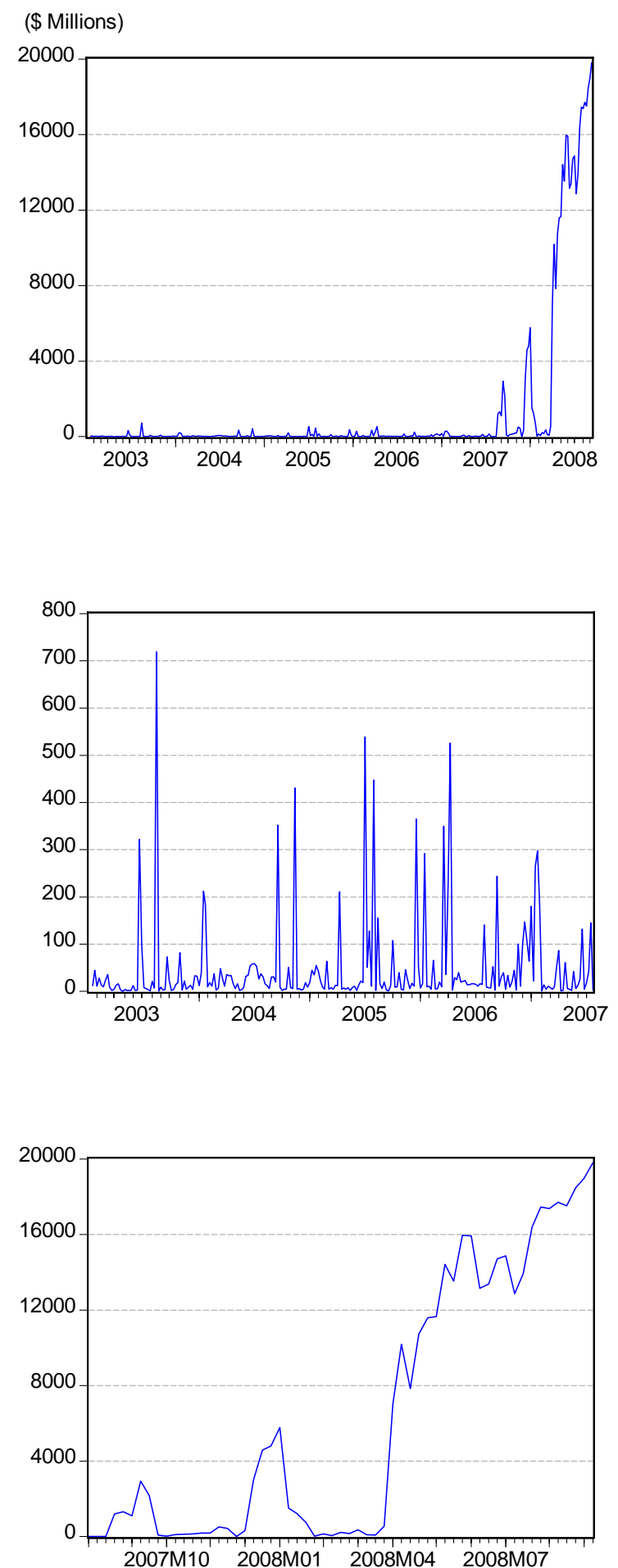
Figure 2: Daily High Funds Rate and the Primary Credit Rate

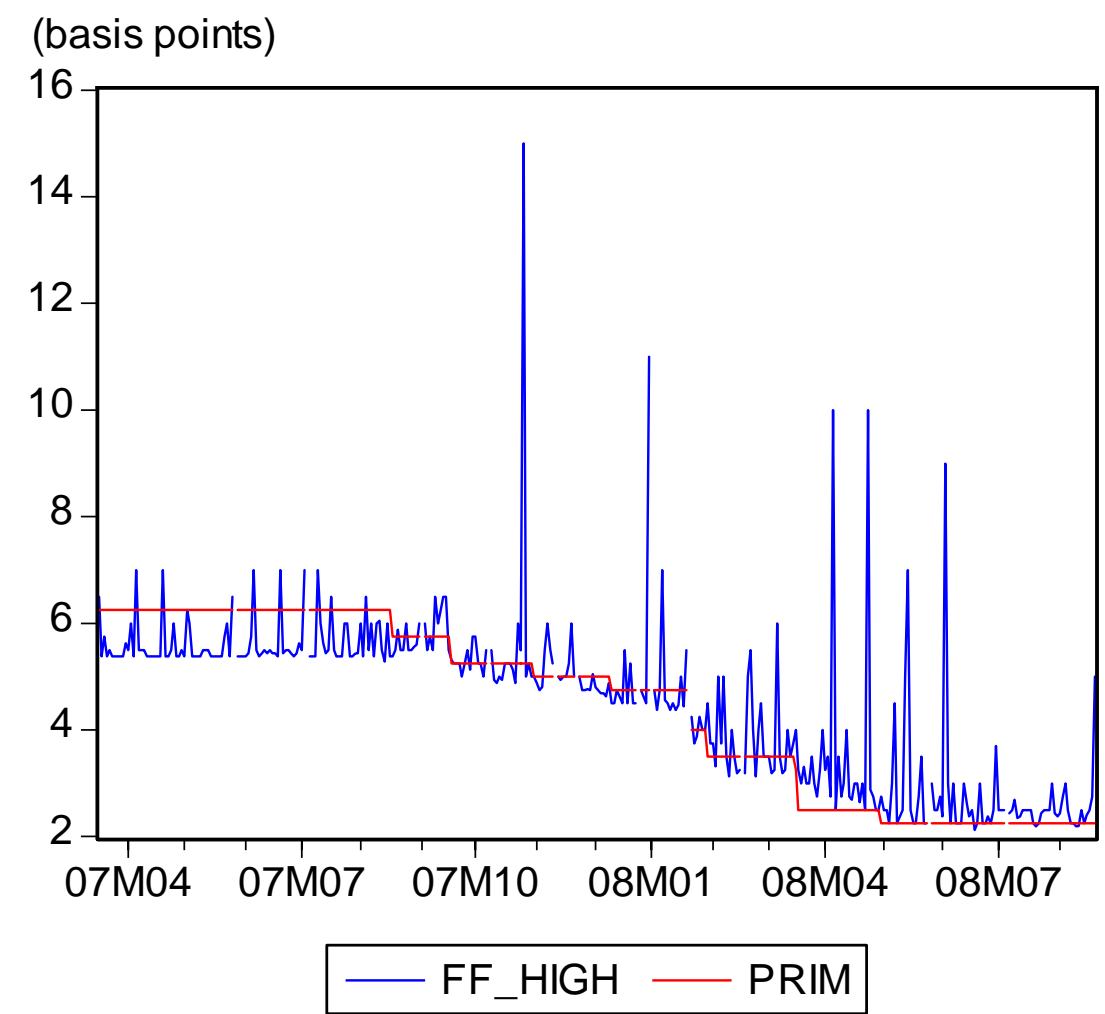

where FF_HIGH: Daily high funds rate

PRIM: Primary Credit rate 
Figure 3: Distribution of Banks and their Reserves

\section{Excess}

Reserves

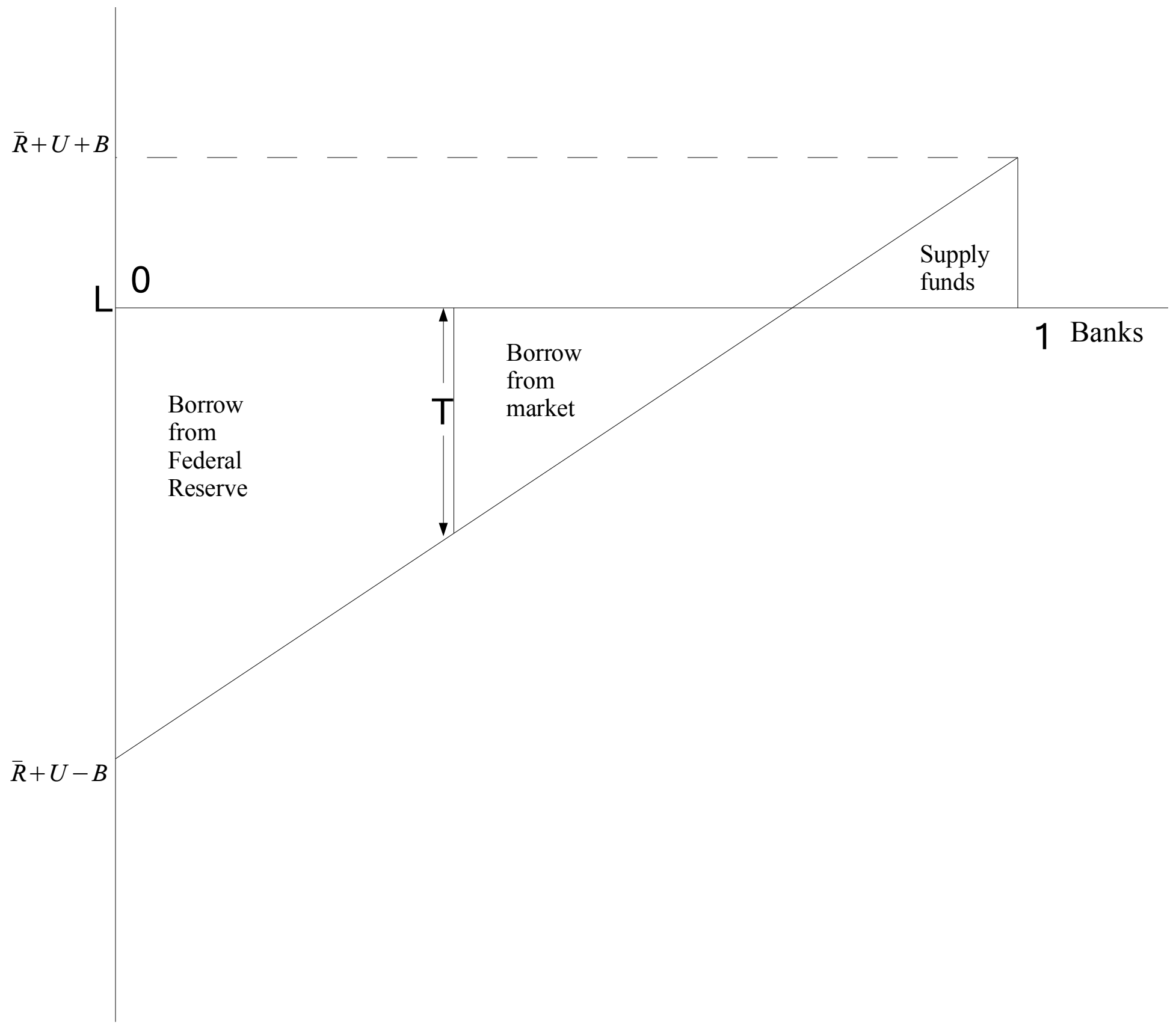




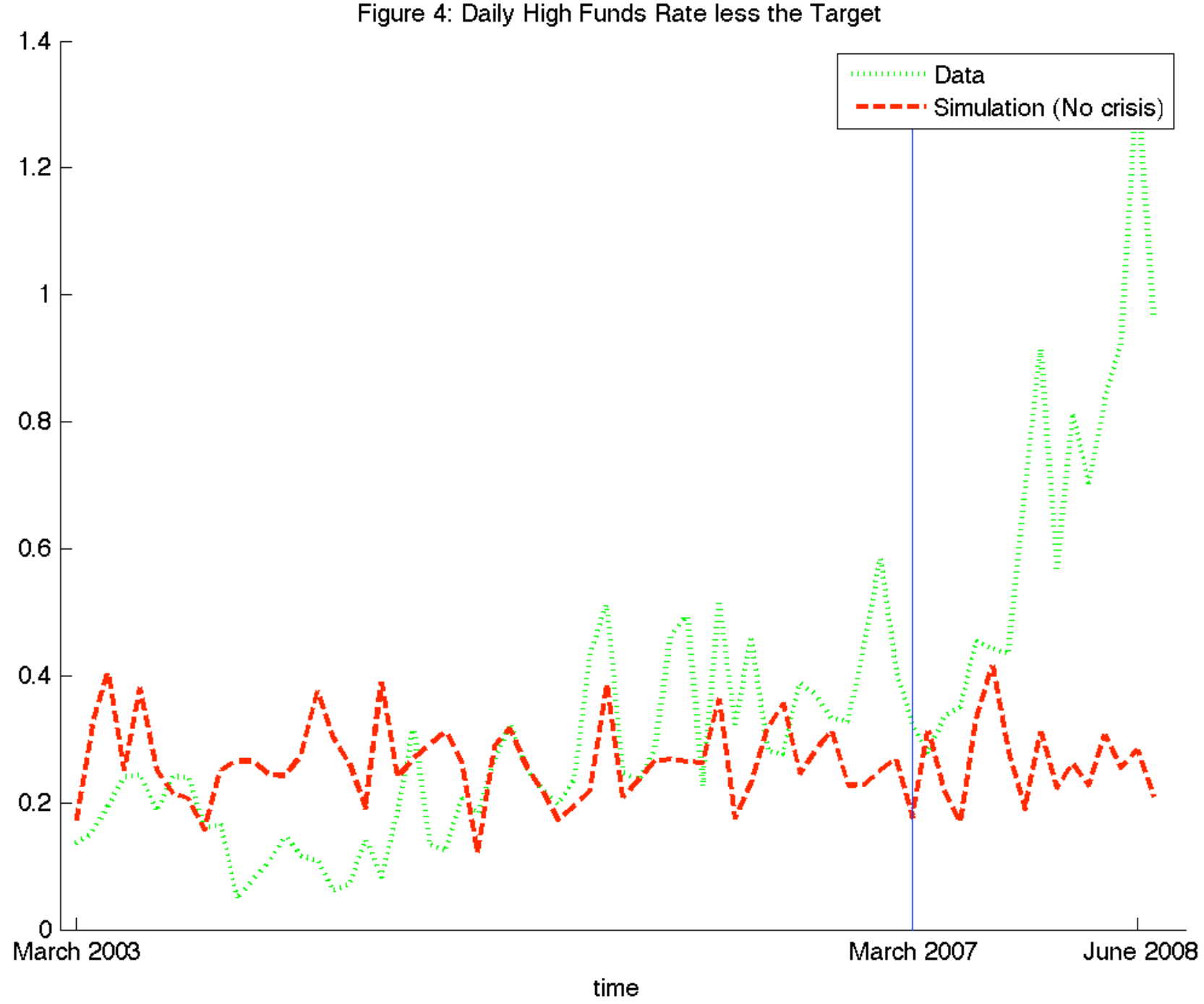




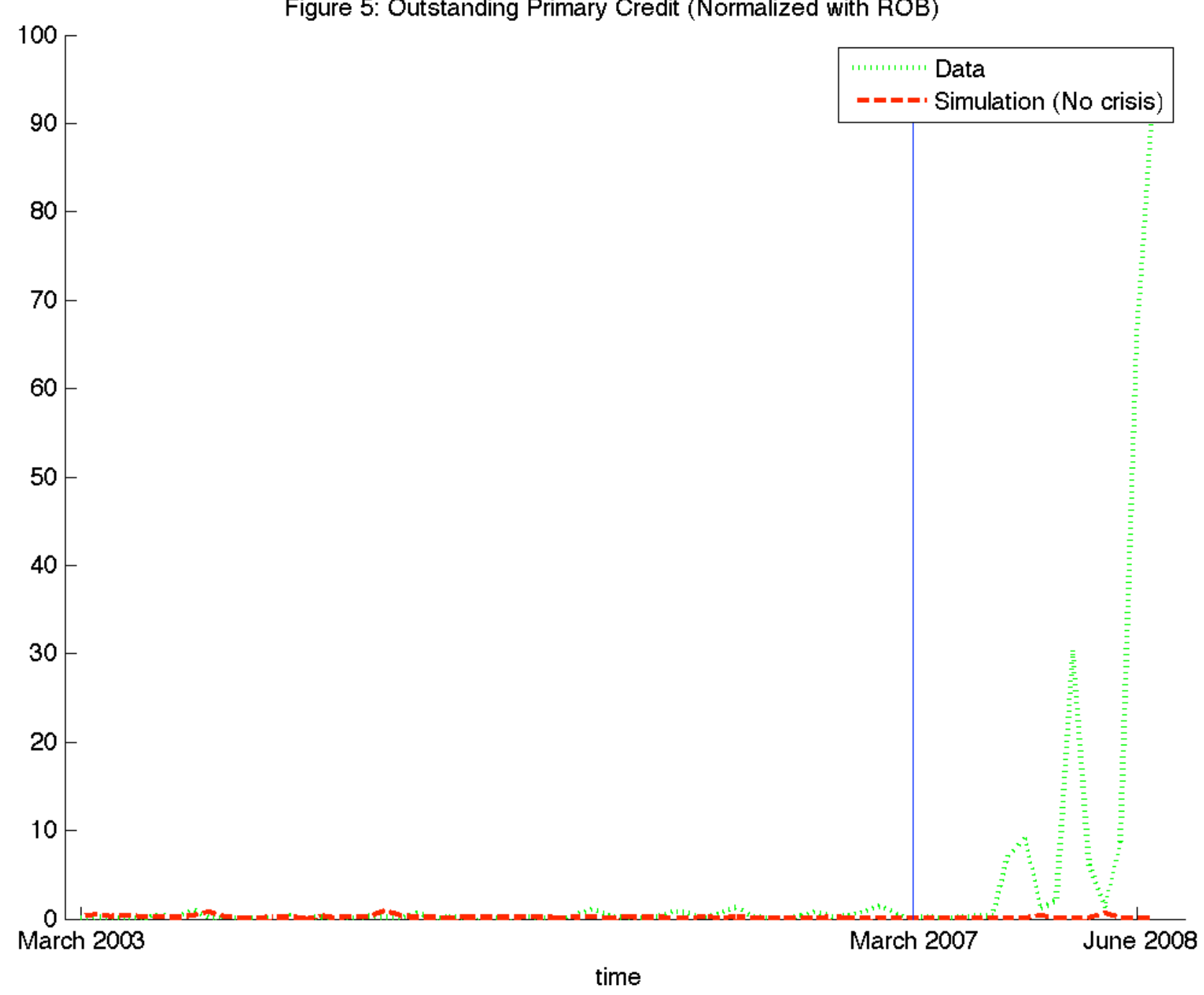




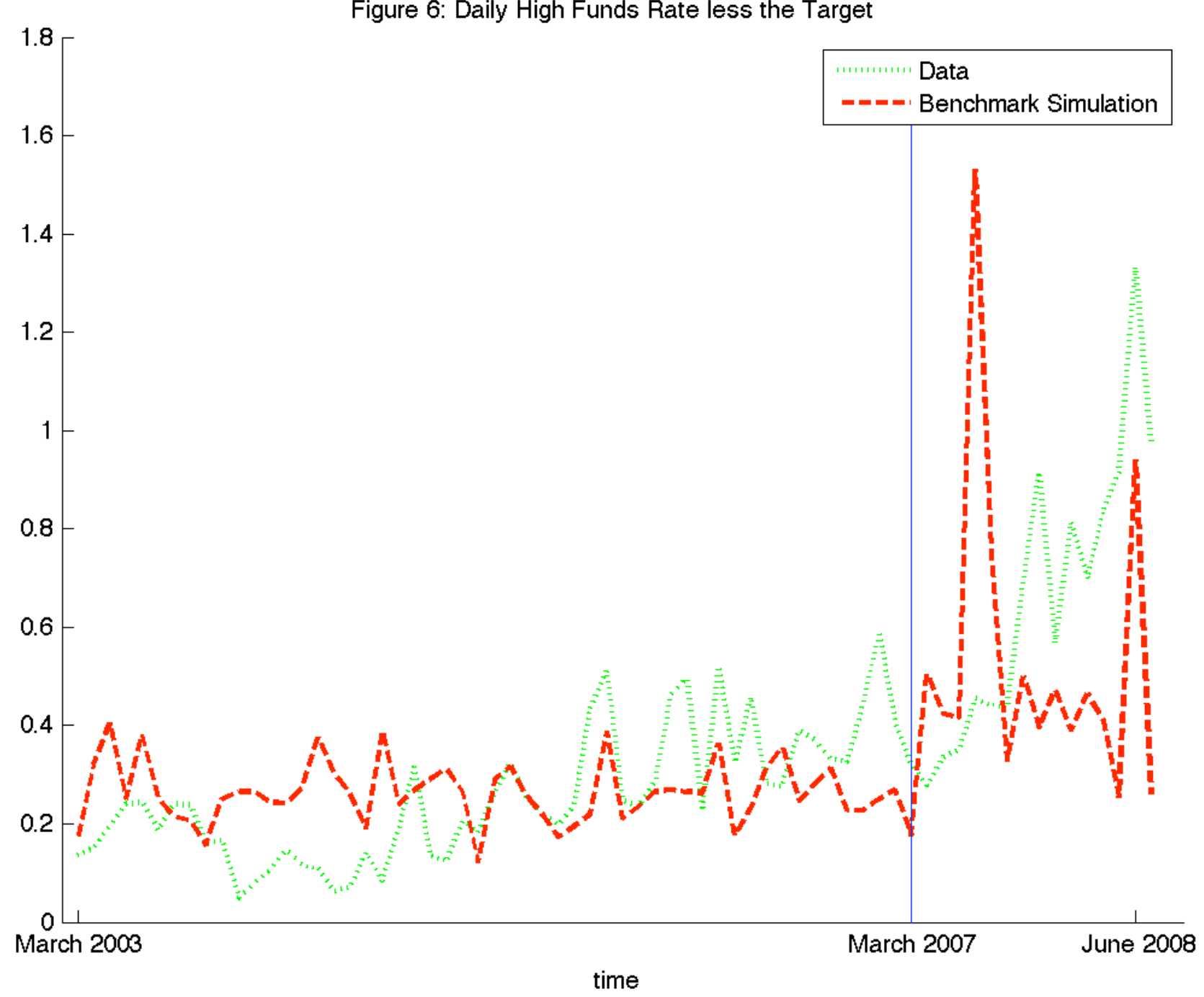




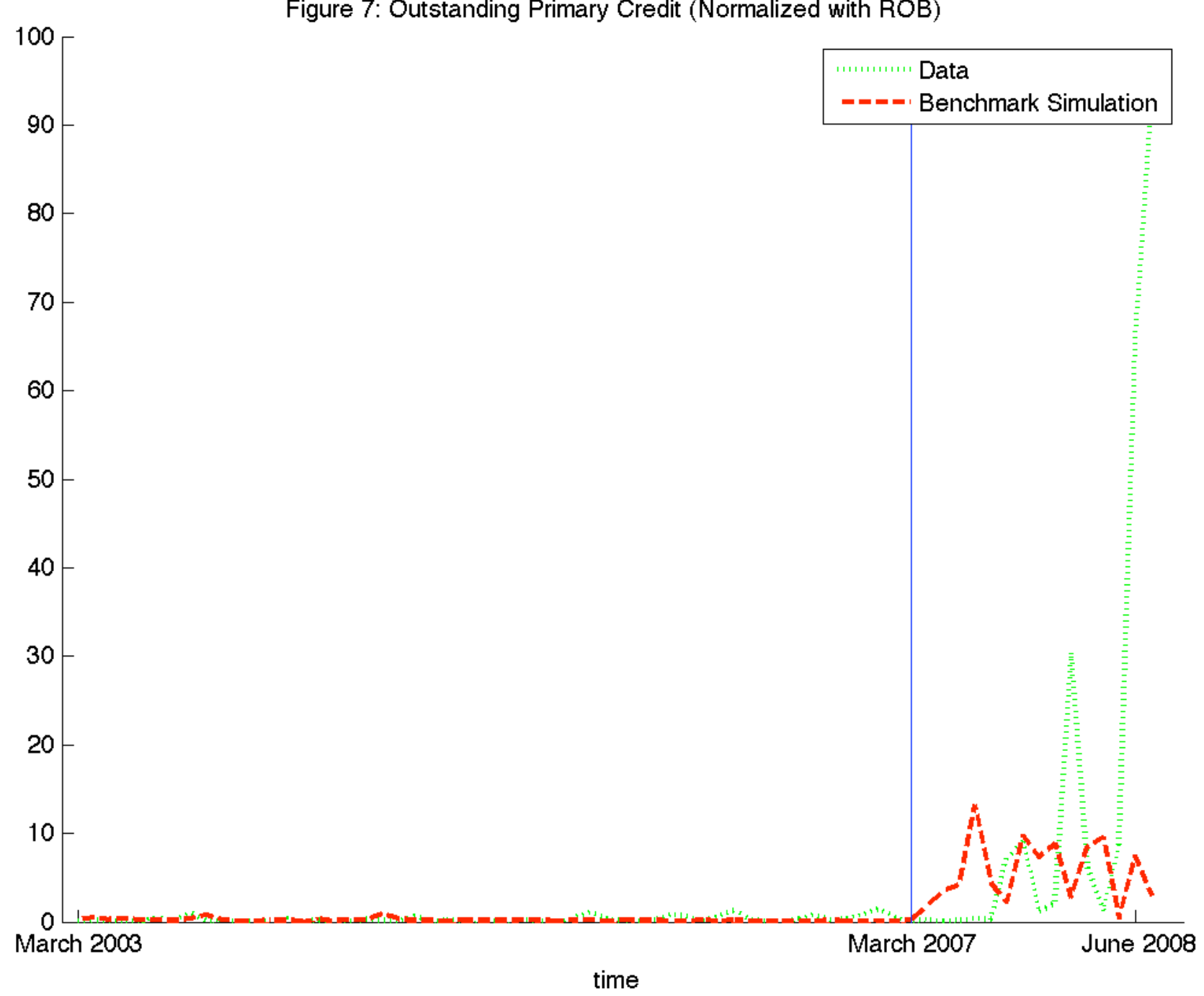




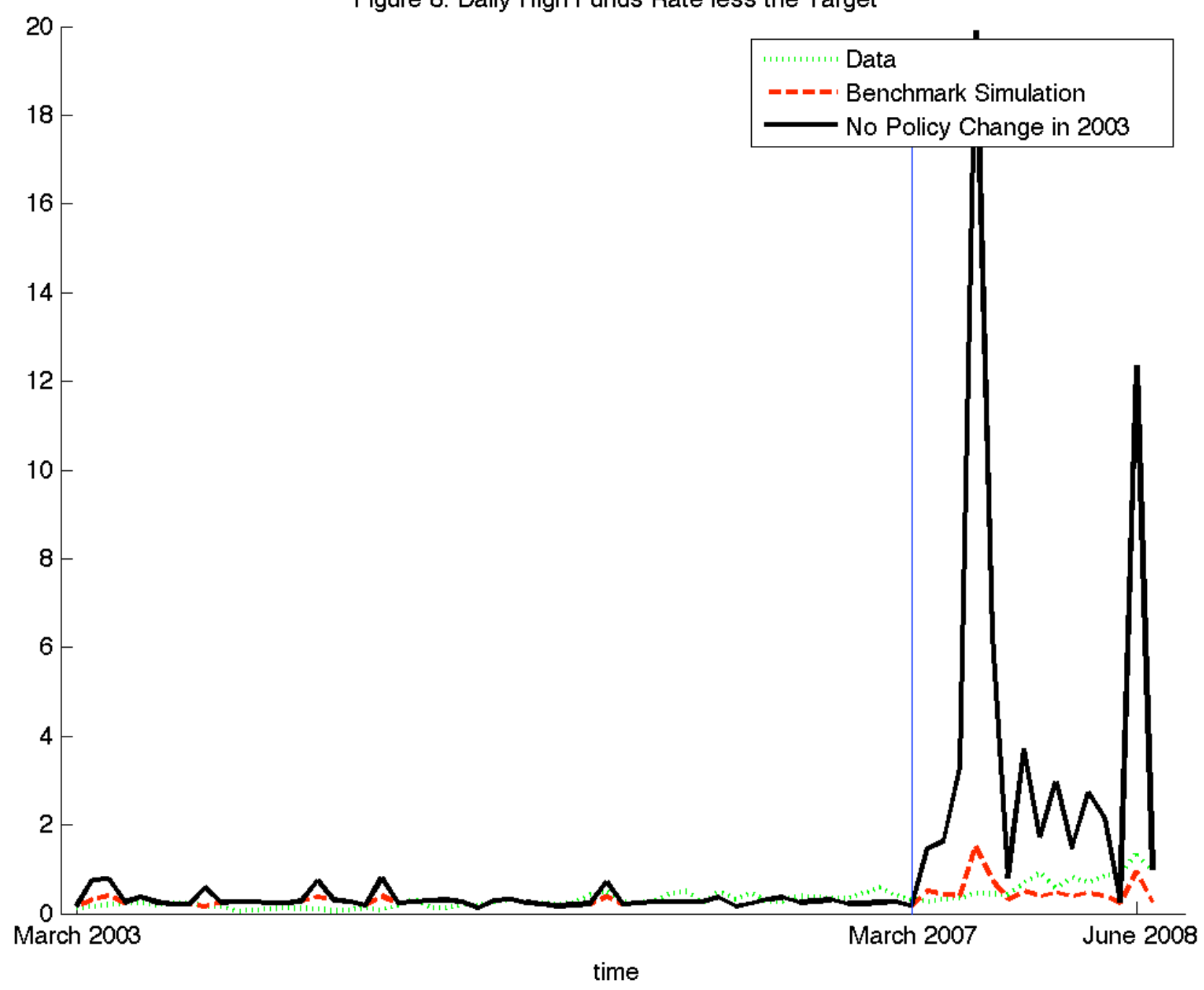




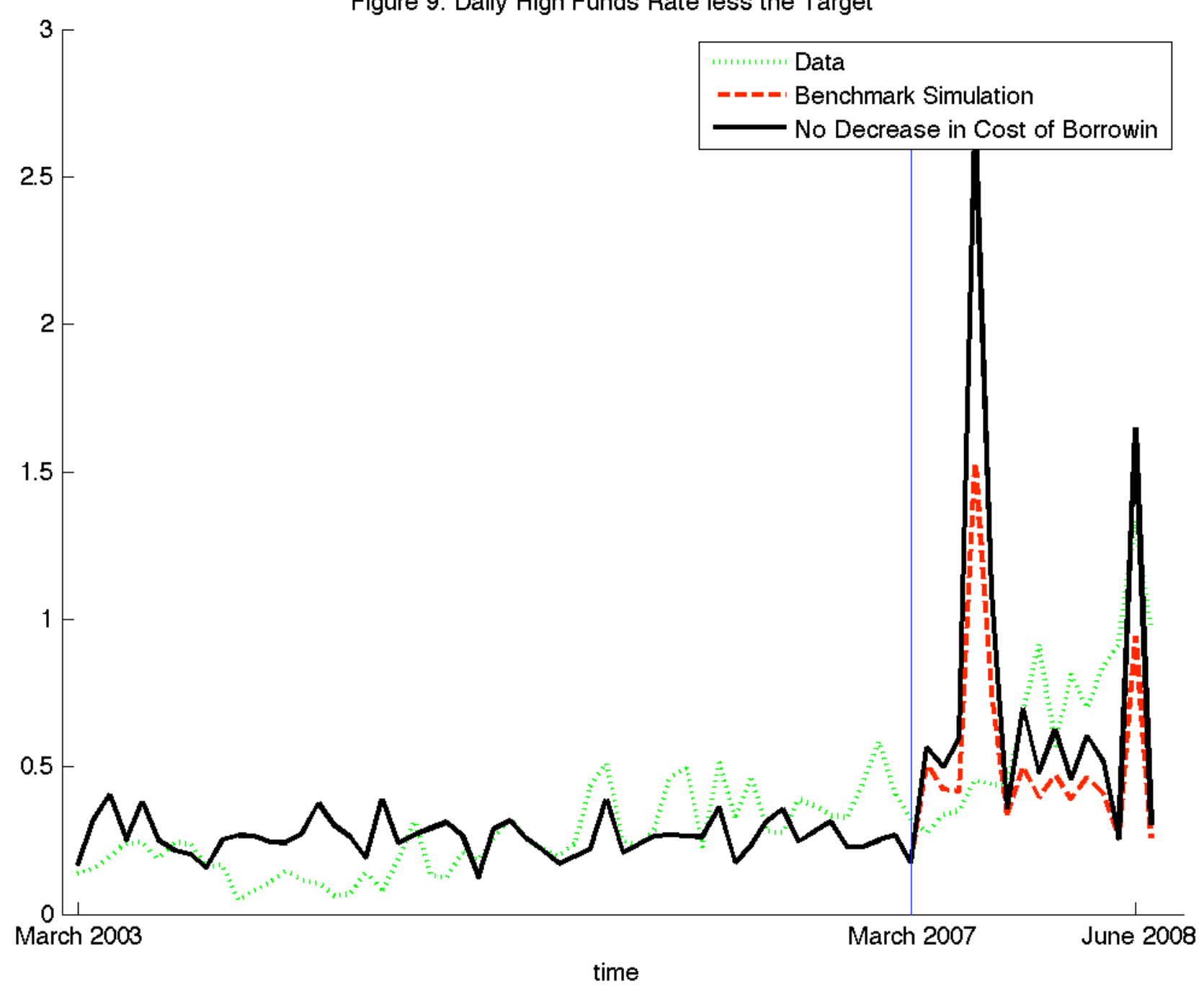




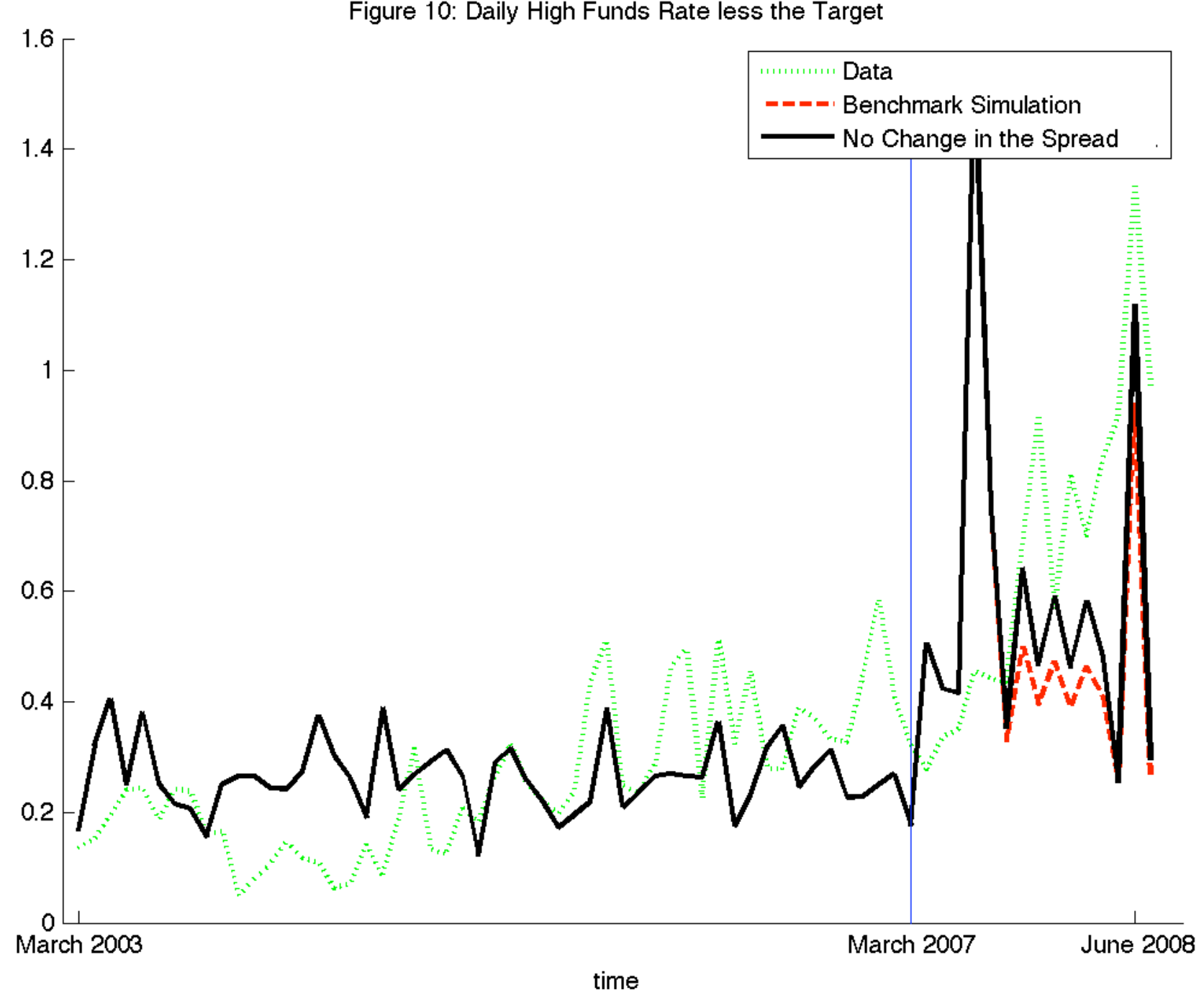




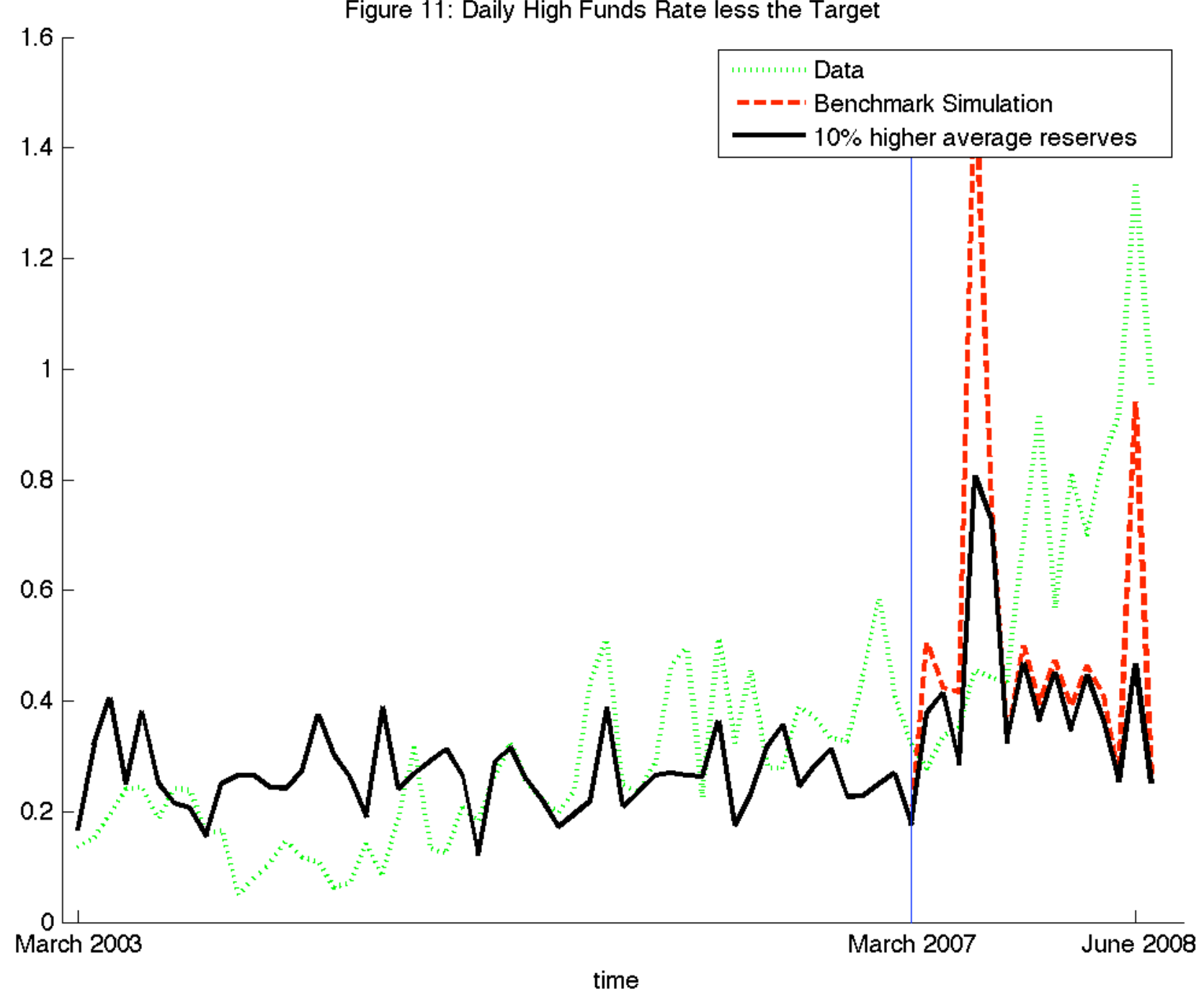




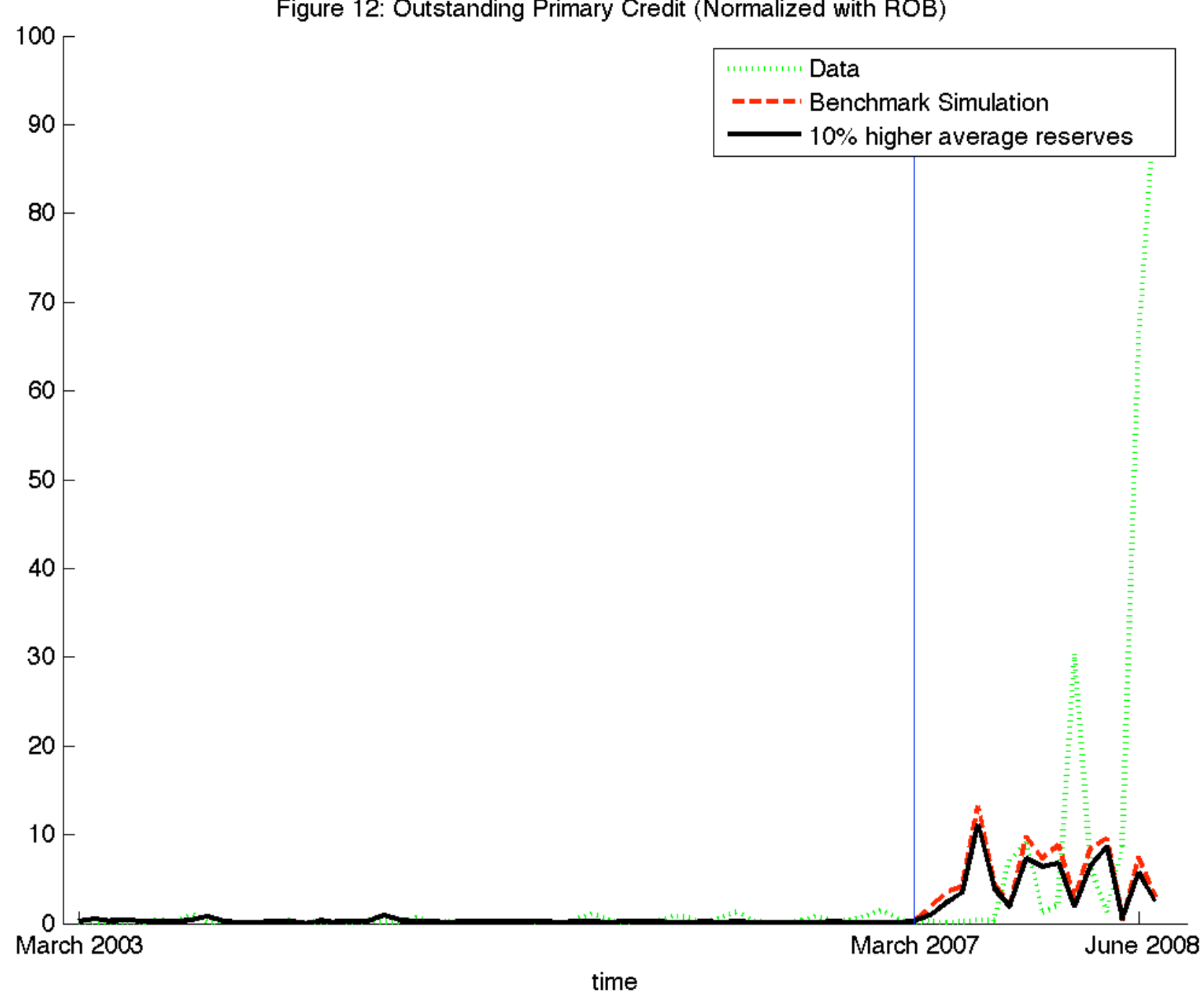




\section{Appendix}

The first two panels of Table A1 present the OLS estimates of the auxiliary model parameters using the actual as well as the simulated data along with the mean and the variance of borrowing and $\tilde{r}_{t}$. Comparing the second and the fourth columns in the first panel, we note that the auxiliary model's estimates from the simulated data and the actual data are pretty close to each other since the algorithm minimizes the distance between those two estimates. However, they are not identical since the auxiliary model has more parameters than the true underlying model. As shown in the fifth row, borrowing responsiveness to the interest rate spread $\left(\tilde{r_{t}}\right)$ increases significantly after the policy change in 2003 consistent with a decline in the market stigma and the revival of the borrowing function. The second panel provides a similar comparison between the moments generated by the simulated data (column 2) and those computed from the actual data (column 4). Similar to the first panel, the two sets of statistics display a strong resemblance.

The third panel of Table A1 exhibits the parameter estimates of the true underlying model and their standard errors. The most interesting parameters for our purposes are displayed in the first two rows. Notice that the implicit fixed cost of borrowing declines about 90 percent (from $c_{1}=0.054$ to $c_{1}+c_{2}=0.007$ ) after the policy change in 2003. This is strong evidence that the Fed's new policy was indeed successful in reducing the stigma associated with discount window borrowing. In addition to estimating the fixed cost of borrowing from the discount window, we are also interested in determining whether this implicit cost exhibits any gradual changes over time. In particular, one may expect a gradual decline in the implicit cost of borrowing in the post-2003 period, due to the market's slow adjustment to the new regime. In order to address this issue, we experimented with an alternative model 
which allows a time trend in the implicit cost of borrowing prior to and after 2003 (not shown). However, the trend terms associated with the implicit cost of borrowing were not significant in either sample. This finding suggests that there may not be a gradual adjustment to the new regime in the second sample, similar to our finding in the previous section. We believe that our results may be driven by the fact that we do not have a sufficient number of observations to identify such a time trend.

The third row shows that the aggregate reserve shock $U_{t}$ changes between 0.43 and +0.43 in the beginning of the sample, while the bank specific reserve shock $V_{t}^{i}$ varies between -0.34 and 0.34 initially (row 4). Rows 5 and 6 show that there is a significant time trend in these shocks. In fact, when we substitute the estimates for $D$ and $E$ in equation 3, we observe that the aggregate reserve shock exhibits a negative trend while the bank specific shock exhibits a positive trend. The estimate of $E$ implies that the standard error of $U_{t}$ decreases about $0.05 \%$ per year while the estimate of D implies that the range of $V_{t}^{i}$ increases about 15\% every year. The mild negative time trend in the aggregate shock, $U_{t}$, could reflect improvements in the Desk's reserve management ability over time as we noted in the previous section.

Row 7 exhibits that the estimated ratio of banks that incur a technical problem, and thus are forced to borrow from Fed rather than the market, vary from 0 to 0.04 , indicating that not more than $4 \%$ of the banks are affected by this type of a problem at a given point in time. The last row indicates that banks aim to attain a higher level of balances on the last day of the maintenance period, consistent with our expectations. 
Table A1: Indirect Inference and Auxiliary Model Estimations

\begin{tabular}{|c|c|c|c|c|}
\hline \multicolumn{5}{|c|}{ PANEL 1: AUXILIARY OLS REGRESSION } \\
\hline & \multicolumn{2}{|c|}{ Actual Data } & \multicolumn{2}{|c|}{ Simulated Data } \\
\hline & Coefficient & Std. Err. & Coefficient & $\begin{array}{l}\text { Std. } \\
\text { Err. }\end{array}$ \\
\hline 1. $\quad \underset{\sim}{\text { Constant }}$ & $0.48^{* *}$ & 0.07 & $0.53 * *$ & 0.04 \\
\hline 2. $r_{t}$ & $0.26 * *$ & 0.05 & $0.35 * *$ & 0.03 \\
\hline 3. $(1 / 100) \times T$ & $-0.04 * *$ & 0.01 & $-0.05^{* *}$ & 0.004 \\
\hline 4. $\quad(1 / 100) \times T \times \tilde{r}_{t}$ & $0.06^{* *}$ & 0.01 & $0.05^{* *}$ & 0.005 \\
\hline 5. $D^{2003} \times \tilde{r}_{t}$ & $0.86 * *$ & 0.22 & $1.01 * *$ & 0.10 \\
\hline 6. $D^{\text {Settl.Wed. }}$ & $0.46 * *$ & 0.11 & $0.48 * *$ & 0.07 \\
\hline
\end{tabular}

\begin{tabular}{|c|c|c|}
\hline \multicolumn{3}{|c|}{ PANEL 2: MOMENTS } \\
\hline & Actual Data & Simulated Data \\
\hline 1. $\operatorname{Mean}(\varsigma)$ & 0.46 & 0.45 \\
\hline 2. $\operatorname{Mean}\left(r_{t}\right)$ & 0.42 & 0.37 \\
\hline 3. $\operatorname{Mean}\left(\tilde{r}_{2 t}\right)$ & 0.25 & 0.25 \\
\hline 4. $\operatorname{Var}(\varsigma)$ & 3.01 & 2.15 \\
\hline 5. $\operatorname{Var}\left(\tilde{r}_{t}\right)$ & 1.14 & 1.93 \\
\hline 6. $\operatorname{Var}\left(\tilde{r_{2 t}}\right)$ & 0.14 & 0.08 \\
\hline
\end{tabular}

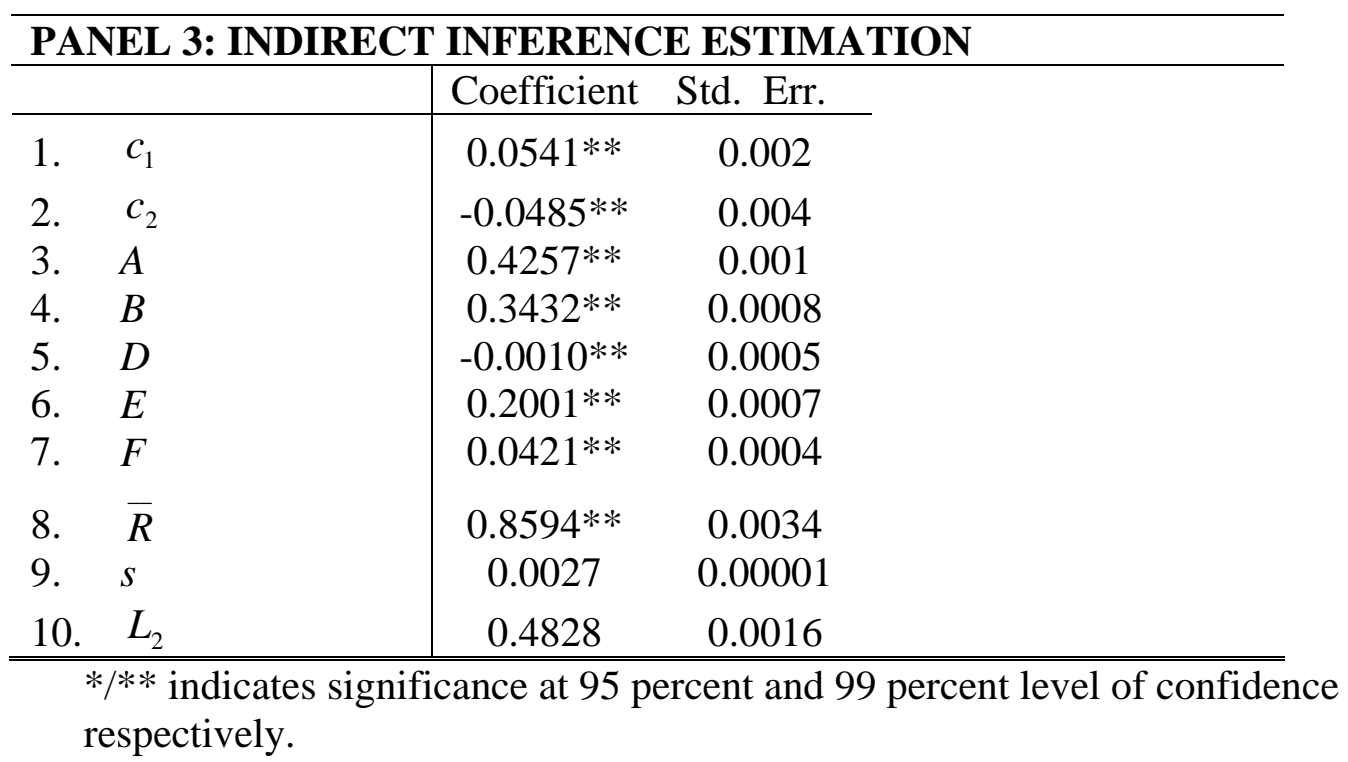

where

$\begin{array}{ll}\varsigma & \text { Normalized borrowing from the Fed } \\ \tilde{r}_{t} & \text { Daily high funds rate minus the target rate } \\ \tilde{r}_{2 t} & \text { Lowest } 50 \% \text { of daily high funds rate less the target rate }\end{array}$


Time trend

$D^{2003}$

$D^{\text {Settl.Wed. }}$

Dummy variable for the period after January 6, 2003

$C_{1}$

Dummy variable for the last day of the maintenance period

$C_{2}$ Implicit cost prior to 2003

$C_{2}$

Implicit cost after 2003

$B \quad$ Interval parameter for the bank specific shock

Interval parameter for the aggregate shock

$D \quad$ Time trend parameter for the aggregate shock

E Time trend parameter for the bank specific shock

$F \quad$ Interval parameter for the probability of a technical problem

$\bar{R} \quad$ Average reserve balances

$S \quad$ Variance of the noise parameter for the daily high funds rate

$L_{2}$

Implicit reserve target on the last day of the maintenance period 